\title{
Knowledge, Attitude and Practice of Tooth Morphology among the Dentists of Kathmandu
}

Chaulagain $\mathrm{R}^{1^{*}}$

${ }^{1}$ Department of Oral Pathology, Chitwan Medical College, Bharatpur, Nepal

\begin{abstract}
Background: Dental anatomy is taught as a basic dental subject in dental schools of Nepal. The knowledge has immense use in clinical practice in dentistry. However, few people feel that it has no use and should be removed from the dental curriculum. The objective of the study was to analyse the knowledge, attitude and practice of tooth morphology among dental practitioners in Kathmandu.

Materials and Methods: A cross-sectional study was undertaken among the dental practitioners in Kathmandu using a self-administered questionnaire to collect the data. In total 300 questionnaires were distributed. The results were analysed for descriptive statistics using the Statistical Package for the Social Sciences (SPSS) 16 software.

Results: A total of 249 responses from the dental practitioners were received. In total $77.9 \%$ of participants strongly agreed that understanding tooth morphology helped in identification of primary and permanent teeth. More than $90 \%$ had positive response regarding its use in day to day clinical practice.

Conclusion: The present study revealed that the dental practitioners have adequate knowledge of tooth morphology and agree on its importance in professional dental practice.
\end{abstract}

Key words: dental anatomy; tooth carving; tooth morphology.

\section{Introduction}

$\mathrm{T}$

The dental anatomy is an important component of dental curriculum in the programs of dentistry in Nepal. It deals with the development, morphological and functional aspect of both primary and permanent dentition. The knowledge of tooth morphology forms the fundamental basis for all the fields of dentistry. ${ }^{1}$ Tooth impart many important functions in human life. It is important for mastication, phonation, speech and also provide esthetic value to our face. ${ }^{2}$ Knowledge of tooth anatomy is important as it, in turn plays vital role during

Conflict of Interest: No

*Corresponding Author
Dr. Rajib Chaulagain
Department of Oral Pathology
Chitwan Medical College, Bharatpur, Nepal
Email: chaulagain.rajib@cmc.edu.np

Dr. Rajib Chaulagain

Chitwan Medical College, Bharatpur, Nepal

Email: chaulagain.rajib@cmc.edu.np restorative treatment, to achieve functional occlusal relationship, esthetics, phonetics and forensic investigations. ${ }^{1}$

Various dental practitioners opine differently regarding the importance of tooth anatomy in future dental practice. Some think learning tooth morphology is waste of time, energy, kilos of wax and further make student a technician. ${ }^{3-5}$

Hence the present study was aimed to analyse knowledge, attitude and practice of dental practitioners in Kathmandu regarding tooth morphology.

\section{Materials and methods}

A cross-sectional study was designed and conducted among the dental practitioners of Kathmandu. The study was conducted for a period of 4 months starting from September 2018 to December 2018 after obtaining the ethical clearance from Institutional Review 
Committee of KIST Medical College and Hospital (IRC NO: 2075/76/45).

Semi-structured questionnaire was developed after reviewing and modifying the related literature ${ }^{6}$ to obtain the information regarding the knowledge, attitude and practice of tooth morphology. The adequacy and the accuracy of the content was also established by consulting the experts related to the field. The questionnaire which was in English language consisted of two parts, the first part consisted of demographic details of the participants and the second part was regarding the knowledge, attitude and practice of tooth morphology. Before sample collection, a pilot study was done among 20 dentists. The convenience sampling method was used to collect the data. The participants were assured of the confidentiality of the information provided and those who agreed to take part in the study the objective of the study was explained. Informed consent was taken followed by distribution of questionnaires. Three-hundred questionnaires were distributed among the dental practitioners working in different hospitals, medical colleges and clinics. Participants who did not give informed consent, incompletely filled questionnaires were excluded from the study. Only 249 completely filled questionnaires were obtained at the end. The data was entered in Microsoft excel and later Statistical Package for the Social Sciences (SPSS) 16 software was utilized to calculate the descriptive statistics. The findings were interpreted through frequency and percentage to evaluate the knowledge, attitude and practice of tooth morphology.

\section{Results}

A total of 249 completely filled questionnaires were received in the study giving the response rate of $83 \%$. As shown in Table 1, out of 249 participants, $80(32.1 \%)$ were males and 169 $(67.9 \%)$ were females.
Table 1: Gender wise distribution of dental practitioners

\begin{tabular}{|c|c|}
\hline Sex & Frequency (Percent) \\
\hline Male & $80(32.1 \%)$ \\
\hline Female & $169(67.9 \%)$ \\
\hline
\end{tabular}

More than two thirds $(77.9 \%)$ of participants strongly agreed that understanding tooth morphology helped in identification of primary and permanent teeth. Nearly half of the participants $(47 \%)$ agreed that they could easily differentiate between primary and permanent dentition. About $59.4 \%$ of the participants agreed that they could estimate the chronological age of the patients just by visualising the teeth in oral cavity while 8 (3.2 $\%)$ of the participants disagreed. More than half (51 \%) of participants were confident enough to diagnose tooth anomalies. One hundred six $(42.6 \%)$ of participants agreed that they could identify landmarks in the teeth confidently while more than $60 \%$ answered that they could plan treatment based on the type of dentition (Table 2).

More than $90 \%$ gave positive response that knowing tooth morphology had helped them in day to day clinical practice. One hundred thirty dental practitioners agreed that tooth carving classes have tutored them in registering and retaining the knowledge of tooth morphology effectively. More than half (54.6\%) answered that thorough mentoring helped easy recollection of tooth landmarks while $49.8 \%$ replied that acquaintance with tooth landmarks has become communicating tool among peers and other dentists. One hundred twenty-five participants strongly agreed that tooth morphology plays important role in forensic investigation (Table 2).

Regarding practice more than half (52.6\%) agreed that they could design and perform cavity preparation of tooth effectively due to sound knowledge in measurements and morphology. 
Nearly half of them $(49.8 \%)$ agreed that their subconscious knowledge of tooth morphology had transformed them into a good tooth sculptor while $47 \%$ were confident to apply tooth morphology knowledge as an investigative tool in forensics sciences (Table 2).

Table 2: Knowledge, attitude and practice of tooth morphology among dental practitioners

\begin{tabular}{|c|c|c|c|c|c|}
\hline Questions & $\begin{array}{c}\text { Strongly } \\
\text { agree }\end{array}$ & Agree & Neutral & Disagree & $\begin{array}{l}\text { Strongly } \\
\text { disagree }\end{array}$ \\
\hline \multicolumn{6}{|l|}{ KNOWLEDGE } \\
\hline $\begin{array}{l}\text { Understanding the morphology of tooth helps in } \\
\text { correct identification of primary and permanent teeth }\end{array}$ & 194 (77.9) & $55(22.1)$ & 0 & 0 & 0 \\
\hline $\begin{array}{l}\text { Can easily differentiate primary from permanent } \\
\text { dentition }\end{array}$ & $116(46.6)$ & $117(47)$ & $12(4.8)$ & $4(1.6)$ & 0 \\
\hline $\begin{array}{l}\text { Can estimate the chronological age of a patient by } \\
\text { visualising the teeth present in the oral cavity }\end{array}$ & $63(25.3)$ & $148(59.4)$ & $30(12)$ & $8(3.2)$ & 0 \\
\hline $\begin{array}{l}\text { Confident enough in diagnosing tooth anomalies } \\
\text { because of my sound knowledge of normal tooth } \\
\text { morphology }\end{array}$ & 44 (17.7) & $127(51)$ & $66(26.5)$ & $12(4.8)$ & 0 \\
\hline $\begin{array}{l}\text { Can identify all the landmarks on teeth confidently } \\
\text { because of its reinforcement through carving classes } \\
\text { in a 3D perspective }\end{array}$ & $58(23.3)$ & $106(42.6)$ & 74 (29.7) & $8(7.2)$ & $3(1.2)$ \\
\hline $\begin{array}{l}\text { Can plan treatment for the patient based on the type of } \\
\text { dentition }\end{array}$ & $70(28.1)$ & $158(63.5)$ & $18(7.2)$ & $3(1.2)$ & 0 \\
\hline \multicolumn{6}{|l|}{ ATTITUDE } \\
\hline $\begin{array}{l}\text { Knowing tooth morphology has helped me in my day } \\
\text { to day clinical practice. }\end{array}$ & $116(46.6)$ & $113(45.4)$ & $17(6.8)$ & $3(1.2)$ & 0 \\
\hline $\begin{array}{l}\text { Tooth carving classes have tutored in registering and } \\
\text { retaining the theory knowledge of tooth morphology } \\
\text { effectively }\end{array}$ & $80(32.1)$ & $130(52.2)$ & $36(14.5)$ & $2(0.8)$ & $1(0.4)$ \\
\hline $\begin{array}{l}\text { Due to thorough mentoring, the various general and } \\
\text { specific landmarks of tooth can be easily recollected }\end{array}$ & $56(22.5)$ & $136(54.6)$ & $56(22.5)$ & $1(0.4)$ & 0 \\
\hline $\begin{array}{l}\text { Acquaintance with tooth landmarks has become } \\
\text { networking tool among peers and other dentists }\end{array}$ & $52(20.9)$ & $124(49.8)$ & 67 (26.9) & $5(2)$ & $1(0.4)$ \\
\hline $\begin{array}{l}\text { Knowledge of tooth morphology plays an important } \\
\text { role in forensic investigation }\end{array}$ & $125(50.2)$ & $101(40.6)$ & $23(9.2)$ & 0 & 0 \\
\hline $\begin{array}{l}\text { Reproducing the required esthetics, boosts the } \\
\text { patients' confidence and satisfaction which is a } \\
\text { greatest challenge as well as demand in today's } \\
\text { clinical practice. }\end{array}$ & $126(50.6)$ & $107(43)$ & $13(5.2)$ & $3(1.2)$ & 0 \\
\hline \multicolumn{6}{|l|}{ PRACTICE } \\
\hline $\begin{array}{l}\text { Can design and perform cavity preparation for a } \\
\text { tooth efficiently because of sound knowledge in } \\
\text { measurements and morphology }\end{array}$ & $80(32.1)$ & $131(52.6)$ & 29 (11.6) & $9(3.6)$ & 0 \\
\hline $\begin{array}{l}\text { Subconscious knowledge of tooth morphology has } \\
\text { transformed into a good tooth sculptor }\end{array}$ & 49 (19.7) & $124(49.8)$ & $68(27.3)$ & $7(2.8)$ & $1(0.4)$ \\
\hline $\begin{array}{l}\text { Can modify crown preparation for primary teeth } \\
\text { according to its morphological needs }\end{array}$ & $39(15.7)$ & $118(47.4)$ & $76(30.5)$ & $15(6)$ & $1(0.4)$ \\
\hline $\begin{array}{l}\text { There should not be any deviation from the normal } \\
\text { while carving or restoring the lost tooth structure }\end{array}$ & $36(14.5)$ & $107(43)$ & 77 (30.9) & $26(10.4)$ & $3(1.2)$ \\
\hline $\begin{array}{l}\text { Confident to apply tooth morphology knowledge as } \\
\text { an investigative tool in forensic sciences }\end{array}$ & 39 (15.7) & $117(47)$ & $75(30.1)$ & $17(6.8)$ & $1(0.4)$ \\
\hline
\end{tabular}




\section{Discussion}

This study aimed to evaluate knowledge, attitude and practice of tooth morphology among dental practitioners in Kathmandu. In this study predominance of females was observed. A total of 249 dental practitioners participated in this study out of which $80(32.1 \%)$ were males and $169(67.9 \%)$ were females. The reason may be due to highest number of females study the BDS program which has been justified by the study of Shrestha et al. ${ }^{7}$

Dentistry is completely dependent upon manual skills which is boosted upon by knowledge. Hence it is defined as art and science. ${ }^{8}$ Knowledge of dental anatomy needed in both basic science and clinical practice. In the present study more than two third students strongly agreed that the knowledge of tooth morphology helps in identification of the two dentitions. This was similar to the study done by Patil et al. ${ }^{6}$ It helps the practitioners to identify the particular tooth, differentiate between the two types of human dentition and the associated dental anomalies. In the present study majority of the participants answered that they can easily differentiate between the two types of human dentitions while more than half agreed that they could diagnose tooth anomalies which is in accordance to the study conducted by Patil et al. ${ }^{6}$ This emphasizes the importance of dental anatomy.

The knowledge obtained from tooth morphology in turn helps many dental practitioners in professional careers not only for pleasing appearance but also to achieve functional occlusion. ${ }^{1}$

Dental anatomy in Nepal is taught in all the dental schools of Nepal ( $2^{\text {nd }}$ year in Tribhuvan University and $1^{\text {st }}$ year in Kathmandu University). In Nepal all of the dental schools have been teaching dental anatomy utilizing traditional methods through lectures, books, carving of tooth using wax block which are the most favoured methods used in teaching and learning practices. More than $90 \%$ of the dental students and $96 \%$ of dental practitioners agreed that tooth carving helped them to learn tooth morphology better (unpublished papers). Many studies suggested that carving of the tooth should be discarded from dental syllabus as it is waste of time, energy, greater chances of breakage of the carved specimen during examination and loss of waxes. ${ }^{4}, 5,9,10$ However, few suggested it helped to develop psychomotor skills and manual dexterity. ${ }^{3,11}$ In addition, the knowledge helped in restorative and prosthodontic procedures. ${ }^{3}$

Many studies have suggested to use new methods along with the traditional methods of teaching. ${ }^{12,13}$ Use of macro models of teeth have also been suggested to enhance excellent visualization of morphological characteristics of tooth and occlusion, thus leading to better carving of teeth. ${ }^{14}$ Recently tooth identification puzzle has been introduced as an innovative methods to learn tooth morphology. ${ }^{15}$ Teaching tooth morphology has also been supplemented with digital atlases. ${ }^{11}$ These days newer methods have been utilized as an alternative way to enhance and support the traditional methods such as digital methods utilizing computer graphics methods and online teaching methods have also been adopted in many countries. ${ }^{16,17}$ The use of computer assisted instruction along with traditional wax carving have also been suggested to enhance the learning capacity. ${ }^{17,18}$ The main advantage of the computer assisted method was the possibility to repeat the technique again and again when needed. ${ }^{16,17}$ Analysis of tooth is primary method used in human identification especially in mass disaster and crime site investigation. ${ }^{19}$ For this sound knowledge of tooth morphology is required. Nearly half of the respondents agreed that they were confident enough to apply the tooth morphology knowledge in forensic 
investigations. Patil et al have reported similar findings in their study. ${ }^{6}$

The main limitation of this study was the samples were taken from Kathmandu with convenience sampling technique so generalizability of the study cannot be done.

\section{Conclusions}

The present study revealed that the dental practitioners are positive regarding the importance of tooth morphology. Knowledge of tooth morphology has many applications in professional dental practice. Furthermore, the author suggests the addition of advanced methods in the dental curriculum along with the traditional method so that it may help in future professional practice.

\section{Acknowledgements}

The author would like to acknowledge all the dental practitioners who participated in the study.

\section{References}

1. de Azevedo RA, Correa MB, Torriani MA, Lund RG. Optimizing quality of dental carving by preclinical dental students through anatomy theory reinforcement. Anatomical Sciences Education. 2018;11(4):377-84.

2. Hildebrand $\mathrm{C}$, Fried $\mathrm{K}$, Tuisku F, Johansson C. Teeth and tooth nerves. Prog Neurobiol. 1995;45(3):165-222.

3. Patil PG. Tooth carving: a response. Indian $\mathrm{J}$ Dent Res. 2012;23(5):691-2.

4. Rao A. Tooth carving. Indian J Dent Res. 2010;21(1):146.

5. Sivapathasundharam B. Tooth carving. Indian J Dent Res. 2008;19(3):181.

6. Patil S, Sowmya S, Rao RS, Raj T. Knowledge, attitude and practice of tooth morphology among dental students. Journal of Advanced Clinical and Research Insights. 2015;2(3):12430.

7. Shrestha RM, Shrestha S, Kunwar N. Dentists in Nepal: a situation analysis. Journal of Nepal Health Research Council. 2017;15(2):187-92.
8. Keyworth RG. Dentistry-A Science or an Art? The Journal of the American Dental Association. 1924;11(5):436-8.

9. Baskar P. Tooth carving. Indian J Dent Res. 2009;20(1):130.

10. Ponniah I. Why tooth carving? Indian J Dent Res. 2010;21(3):463.

11. Eid RA, Ewan K, Foley J, Oweis Y, Jayasinghe J. Self-directed study and carving tooth models for learning tooth morphology: perceptions of students at the University of Aberdeen, Scotland. J Dent Educ. 2013;77(9):1147-53.

12. Oweis Y, Eriefej N, Eid RA. Students' Perceptions of Dental Anatomy Course at The University of Jordan. Dent Pract. 2015;49(3):147-54.

13. de Azevedo RdA, da Rosa WLdO, da Silva $\mathrm{AF}$, Correa MB, Torriani MA, Lund RG. Comparative effectiveness of dental anatomy carving pedagogy: a systematic review. J Dent Educ. 2015;79(8):914-21.

14. Siéssere S, Vitti M, Sousa LGd, Semprini M, Regalo SCH. Educational material of dental anatomy applied to study the morphology of permanent teeth. Braz Dent J. 2004;15(3):23847.

15. Risnes S, Khan Q, Hadler-Olsen E, Sehic A. Tooth identification puzzle: A method of teaching and learning tooth morphology. Eur J Dent Educ. 2019;23(1):62-7.

16. Juneja S, Juneja M. Role of computer-based learning in tooth carving in dentistry: An Indian perspective. Int J Appl Basic Med Res. 2016;6(3):164-5.

17. Nance ET, Lanning SK, Gunsolley JC. Dental anatomy carving computer-assisted instruction program: an assessment of student performance and perceptions. J Dent Educ. 2009;73(8):9729.

18. Bogacki RE, Best A, Abbey LM. Equivalence study of a dental anatomy computer-assisted learning program. J Dent Educ. 2004;68(8):86771.

19. Jani G, Johnson A. Tooth reconstruction in forensic situations through dental materials: An anatomical art. J Forensic Dent Sci. 2018;10(3):137-42. 